\title{
Cysteine and glycine-rich protein 2 (CSRP2) transcript levels correlate with leukemia relapse and leukemia-free survival in adults with B-cell acute Iymphoblastic leukemia and normal cytogenetics
}

\author{
Shu-Juan Wang1,*, Ping-Zhang Wang ${ }^{2,}{ }^{1}$, Robert Peter Gale ${ }^{3}$, Ya-Zhen Qin ${ }^{1}$, Yan- \\ Rong Liu' ${ }^{1}$, Yue-Yun Lai ${ }^{1}$, Hao Jiang ${ }^{1}$, Qian Jiang ${ }^{1}$, Xiao-Hui Zhang ${ }^{1}$, Bin Jiang ${ }^{1}$, Lan- \\ Ping $X u^{1}{ }^{1}$ Xiao-Jun Huang ${ }^{1,4}$, Kai-Yan Liu ${ }^{1}$, Guo-Rui Ruan ${ }^{1}$ \\ ${ }^{1}$ Peking University People's Hospital and Institute of Hematology, Beijing Key Laboratory of Hematopoietic Stem Cell \\ Transplantation, Beijing, China \\ ${ }^{2}$ Department of Immunology, School of Basic Medical Sciences, Peking University Health Science Center, Key \\ Laboratory of Medical Immunology, Ministry of Health, China, Peking University Center for Human Disease Genomics, \\ Beijing, China \\ ${ }^{3}$ Hematology Research Center, Division of Experimental Medicine, Department of Medicine, Imperial College London, \\ London, UK \\ ${ }^{4}$ Peking-Tsinghua Center for Life Sciences, Beijing, China \\ "These authors contributed equally to this work
}

Correspondence to: Kai-Yan Liu, email: liukaiyan@medmail.com.cn Guo-Rui Ruan, email: ruanguorui@pkuph.edu.cn

Keywords: acute lymphoblastic leukemia, CSRP2, prognostic factor, relapse, drug resistance

Received: December 10, 2016

Accepted: March 11, 2017

Published: March 21, 2017

Copyright: Wang et al. This is an open-access article distributed under the terms of the Creative Commons Attribution License (CC-BY), which permits unrestricted use, distribution, and reproduction in any medium, provided the original author and source are credited.

\section{ABSTRACT}

Relapse is the major cause of treatment-failure in adults with B-cell acute lymphoblastic leukemia (ALL) achieving complete remission after induction chemotherapy. Greater precision identifying persons likely to relapse is important. We did bio-informatics analyses of transcriptomic data to identify mRNA transcripts aberrantly-expressed in B-cell ALL. We selected 9 candidate genes for validation 7 of which proved significantly-associated with B-cell ALL. We next focused on function and clinical correlations of the cysteine and glycine-rich protein 2 (CSRP2). Quantitative real-time polymerase chain reaction (RT-qPCR) was used to examine gene transcript levels in bone marrow samples from 236 adults with B-cell ALL compared with samples from normals. CSRP2 was over-expressed in 228 out of 236 adults $(97 \%)$ with newly-diagnosed B-cell ALL. A prognostic value was assessed in 168 subjects. In subjects with normal cytogenetics those with high CSRP2 transcript levels had a higher 5-year cumulative incidence of relapse (CIR) and worse relapsefree survival (RFS) compared with subjects with low transcript levels (56\% [95\% confidence interval, 53, 59\%] vs. $19 \%[18,20 \%] ; P=0.011$ and $41 \%[17,65 \%]$ vs. 80\% [66-95\%]; $P=0.007$ ). In multivariate analyses a high CSRP2 transcript level was independently-associated with CIR $(H R=5.32[1.64-17.28] ; P=0.005)$ and RFS $(H R=5.56[1.87,16.53] ; P=0.002)$. Functional analyses indicated CSRP2 promoted cell proliferation, cell-cycle progression, in vitro colony formation and cell migration ability. Abnormal CSRP2 expression was associated with resistance to chemotherapy; sensitivity was restored by down-regulating CSRP2 expression. 


\section{INTRODUCTION}

B-cell acute lymphoblastic leukemia (ALL) is characterized by clonal expansion of developmentallyarrested B-cell precursors [1]. Although survival of adults with B-cell ALL has improved relapse is an important problem. Prognostic models for relapse include age, WBC levels at diagnosis, immune phenotype, cytogenetics, mutational landscape, response to induction therapy and measureable residual disease (MRD) after completing therapy [2]. Adverse cytogenetic and mutations include hypo-diploidy (< 44 chromosomes), $M L L / 11 \mathrm{q} 23$ translocations, complex cytogenetics $(\geq 5$ abnormalities) and $\mathrm{t}(9 ; 22)$ and/or $B C R-A B L 1$ [2]. However, about onehalf of adults with B-cell ALL have none of the adverse prognostic variables at diagnosis making predicting relapse difficult, especially so in those with normal cytogenetics $[3,4]$. Identifying a new prognostic variable in these persons is important [5].

Analyzing differential expression of mRNAs is a new approach to predicting outcomes of persons with B-cell ALL. For example, in adults with B-cell ALL increased CTGF (connective tissue growth factor) and LEF1 (lymphoid enhancer binding factor-1) expression are associated with worse RFS $[6,7]$ whereas increased $B A A L C$ (brain and acute leukemia, cytoplasmic) expression is associated with an unfavorable response to chemotherapy and worse survival [8].

A bioinformatics-based evaluation of candidate mRNAs improves efficiency compared with random sampling [9]. We used publicly available genome-wide mRNA expression data from patients with B-cell ALL to identify differentially expressed transcripts compared with normals. We identified 9 candidate genes 7 of which we validated and focused our attention on CSRP2 (cysteine and glycine-rich protein 2). CSRP2 is a member of CSRP family encoding a group of short LIM domain proteins $(21 \mathrm{kDa})$ which are critical regulators of development and differentiation [10]. The three CSRPs (CSRP1-3) are preferentially expressed in muscle cells localizing to the nucleus and cytoplasm [11]. In the nucleus, they facilitate smooth muscle differentiation via interactions with transcription factors [12]. In the cytoplasm they decorate filamentous actin structures and participate in cytoskeletal remodeling [13]. CSRP2 maps to $12 \mathrm{q} 21$ which is reported abnormal in haematological neoplasms including T-cell ALL and lymphoma [14-16]. Increased CSRP2 transcript levels are associated with dedifferentiation in hepatocellular carcinoma [17]. In microarray-based analyses highexpression of CSRP2 is associated with basal-like breast cancer $[18,19]$. However, there were no reports regarding the role of CSRP2 in hematological neoplasms. Here, we studied levels of CSRP2 transcripts for an association with relapse probability in adults with B-cell ALL. We show increased CSRP2 transcript levels are independentlyassociated with higher cumulative incidence of relapse
(CIR) and worse relapse-free survival (RFS) in adults with B-cell ALL and normal cytogenetics.

\section{RESULTS}

\section{Validation of new biomarkers for B-cell ALL based on genome-wide mRNA analyses}

We studied differentially-expressed genes in normal and B-cell ALL using data from the ImmuSort database (http://immusort.bjmu.edu.cn; Table 1). We focused on the top 20 differentially expressed genes based on the delta values $>45$ and average rank scores (ARSs) $>80$ in B-cell ALL samples. To increase reliability of our analyses we updated these data with relevant data from the Gene Expression Omnibus (GEO) [9]. The final dataset was based on $400 \mathrm{~B}$-cell samples (GEO samples/GSMs, arrays or measurements) from normals and 690 samples from persons with B-cell ALL and confirmed our target gene selection.

Differentially-expressed genes meeting our threshold included $C T G F$ (connective tissue growth factor), ZNF423 (zinc finger protein 423), VPREB1 (pre-B lymphocyte 1), SLC22A16 (solute carrier family 22 member 16), ERG (ETS transcription factor), IGFBP7 (insulin like growth factor binding protein 7), FLT3 (fms related tyrosine kinase-3), DNTT (DNA nucleotidyl exotransferase), SPRY2 (sprouty RTK signaling antagonist 2), CLEC11A (C-type lectin domain family 11 member A) and DBN1 (drebrin-1). Expression of several of these genes such as CTGF and DNTT (TdT) are reported to correlate with therapy-outcomes of persons with B-cell ALL [6, 20-29]. Consequently, we focused on 9 previously-unstudied genes including C5orf62 (SMIM3; small integral membrane protein 3), GNA15 (G-protein subunit alpha 15), CSRP2, $H B E G F$ (heparin binding $E G F$ like growth factor), $R A S D 1$ (RAS-related dexamethasone induced-1), CPNE2 (copine-2), FRMD4B (FERM domain containing 4B), C19orf77 (SMIM24; small integral membrane protein 24) and COL5A1 (collagen type-V alpha-1 chain; Table 1 and Figure 1).

Next we used RT-qPCR to verify differential mRNA levels of these genes in bone marrow cells from 26 adults with newly-diagnosed B-cell ALL compared with cells from 23 normals (Figure 2A). mRNA levels of CSRP2, COL5A1, RASD1 and C5orf62 were significantly increased whereas HBEGF, GNA15, FRMD4B, C19orf77 and $C P N E 2$ were not.

Our re-analysis of cases of B-cell ALL in ImmuSort revealed most samples were from children with B-cell ALL. Consequently, we re-searched the GEO database and found the GSE34861 dataset was from adults with B-cell ALL (191 GSMs) [30]. However, this dataset was not derived from the Affymetrix Human Genome U133 Plus 2.0 Array platform (GEO platform/GPL570) but from the NimbleGen Human Expression Array (GPL15088) 
Table 1: Gene expression levels of the selected top 20 genes with differential expression

\begin{tabular}{|c|c|c|c|c|c|c|c|c|}
\hline & Gene ID & $\begin{array}{c}\text { B-cell } \\
\text { ALL } \\
\end{array}$ & B-cell & Delta & $\begin{array}{l}\text { B-cell } \\
\text { ALL }^{\mathrm{a}} \\
\end{array}$ & B-cell ${ }^{a}$ & Delta $^{a}$ & $\begin{array}{c}\text { B-cell } \\
\text { CLL } \\
\end{array}$ \\
\hline$D N T T$ & 1791 & 97.3 & 45.25 & 52.05 & 99.00 & 47.28 & 51.72 & 42.39 \\
\hline$C 50 r f 62^{b}$ & 85027 & 97.13 & 47.78 & 49.35 & 97.11 & 50.27 & 46.84 & 52.62 \\
\hline$G N A 15^{b}$ & 2769 & 94.21 & 44.21 & 50 & 95.02 & 45.13 & 49.89 & 47.05 \\
\hline VPREB1 & 7441 & 93.07 & 30.73 & 62.34 & 89.57 & 33.17 & 56.40 & 25.72 \\
\hline$C S R P 2 b$ & 1466 & 91.75 & 43.77 & 47.98 & 92.55 & 43.16 & 49.39 & 38.69 \\
\hline$E R G$ & 2078 & 90.97 & 36.54 & 54.43 & 92.32 & 34.78 & 57.54 & 35.76 \\
\hline FLT3 & 2322 & 90.64 & 37.59 & 53.05 & 91.01 & 38.50 & 52.51 & 56.06 \\
\hline IGFBP7 & 3490 & 90.24 & 35.91 & 54.33 & 88.47 & 33.91 & 54.56 & 44.68 \\
\hline$H B E G F^{b}$ & 1839 & 89.86 & 39.48 & 50.38 & 90.75 & 41.42 & 49.33 & 42.88 \\
\hline SPRY2 & 10253 & 89.27 & 38.67 & 50.6 & 89.73 & 33.85 & 55.88 & 60.34 \\
\hline$R A S D 1^{b}$ & 51655 & 89.25 & 41.85 & 47.4 & 92.93 & 40.56 & 52.37 & 52.62 \\
\hline$C P N E 2^{b}$ & 221184 & 89.24 & 37.13 & 52.11 & 89.45 & 37.14 & 52.31 & 40.25 \\
\hline ZNF423 & 23090 & 87.66 & 23.05 & 64.61 & 86.55 & 22.73 & 63.82 & 20.50 \\
\hline$F R M D 4 B^{b}$ & 23150 & 87.47 & 28.57 & 58.9 & 89.47 & 27.75 & 61.72 & 36.59 \\
\hline$D B N 1$ & 1627 & 85.85 & 37.34 & 48.51 & 87.18 & 38.32 & 48.86 & 48.35 \\
\hline CLEC11A & 6320 & 85.67 & 36.54 & 49.13 & 87.63 & 41.00 & 46.63 & 29.93 \\
\hline C19orf $77^{b}$ & 284422 & 84.8 & 30.51 & 54.29 & 84.85 & 34.01 & 50.84 & 28.16 \\
\hline SLC22A16 & 85413 & 84.63 & 28.3 & 56.33 & 85.99 & 27.33 & 58.66 & 30.61 \\
\hline$C T G F$ & 1490 & 83.18 & 31.71 & 51.47 & 83.32 & 36.01 & 47.31 & 14.16 \\
\hline COL $5 A 1^{b}$ & 1289 & 81.38 & 31.69 & 49.69 & 85.45 & 36.79 & 48.66 & 29.17 \\
\hline
\end{tabular}

a Updated B-cell ALL (690 GSMs) and normal B-cell (400 GSMs) samples. The rest represent samples from B-cell ALL (314 GSMs), B-cell chronic lymphoid leukemia (B-cell CLL; 767 GSMs) and B-cells without B-cell ALL and B-cell CLL samples (B-cell; 464 GSMs include 400 samples from normals and 64 samples from other diseases).

${ }^{b} 9$ selected genes without functional reports relevant to B-cell ALL. Values indicate average rank scores (ARSs) of genes in their respective samples.

despite the fact both platforms include genome-wide transcriptome arrays. We next rank-normalized the dataset to derive ARS values for these genes as described [9]. We found all genes shown in Table 1 except C19orf77 not included in the GPL15088 platform were also upregulated. FRMD $4 B$ had the lowest ARS value (61.76) and the remaining genes had ARS values $>75$.

Because our RT-qPCR validation studies used $A B L 1$ as an internal control we compared $A B L 1$ expression in children and adults with B-cell ALL. ABL1 mRNA levels were dramatically higher in adults with B-cell ALL with ARS $\geq 93$ compared with children B-cell ALL with ARS $\geq 86$ (Supplementary Figure 1). Consequently, we switched to a GAPDH (glyceraldehyde-3-phosphate dehydrogenase) internal control and re-studied 9 genes 7 of which were upregulated (Figure 2B). There were insufficient data to critically-analyze $F R M D 4 B$ and $C P N E 2$ which had Q3 values which skewed higher than controls (Figure 2B). CSRP2 was the most differentially expressed gene in our validation studies (Figure 2).

\section{CSRP2 transcript levels in B-cell ALL}

CSRP2 transcript levels were significantly higher in B-cell ALL cell lines (BV173, Sup-B15 and BALL-1) and a mantle cell lymphoma cell line (MAVER) compared with T-cell ALL cell lines (6T-CEM, MOLT4), a chronic myeloid leukemia cell line (K562), acute myelogenous leukemia (AML) cell lines (KG-1, NB4, HL60) or other lymphoma cell lines (U937, Raji, Ramos; Figure 3A and Supplementary Table 1).

Next we studied bone marrow samples from subjects with B-cell ALL at diagnosis. CSRP2 transcript levels were significantly higher (median 53\%; range $0-1066 \%$ ) compared with levels in 43 normals $(0.44 \%$; $0-1.78 \%$; $P<0.0001$; Figure 3B). Receiver-operator characteristic (ROC) curve analyses identified an area under the curve (AUC) for CSRP2 transcript levels of 0.980 (95\% confidence interval [CI], 0.964, 0.996; $P<0.0001)$ with a maximum CSRP 2 transcript level Youden index of $1.83 \%$. Using this cut-off value the rate of CSRP2 over-expression in newly-diagnosed adult B-cell ALL was $97 \%$. Subjects 
with $M L L$ translocation $(N=11$; median $262 \%$; range 63-995\%) had the highest CSRP2 transcript levels. Subjects with a normal cytogenetics $(N=56 ; 49 \%$ $[0.21,548 \%])$ or BCR-ABL1 $(N=56 ; 42 \%[0.46,269 \%])$ had lower CSRP2 transcript levels (Figure 3C). These results agree with the data set of GSE34861 [30] which included samples from 191 adults with B-cell ALL (Figure 3D).

The subjects were divided into cohorts with high or low CSRP2 transcript levels at the median CSRP2 transcript value. All subjects with an $M L L$ translocation and more subjects with a $\mathrm{WBC}>30 \times 10 \mathrm{E}+9 / \mathrm{L}$ were in the high CSRP2 transcript level cohort (Table 2). There was no significant association between CSRP2 transcript levels and age, sex, platelet level, percent bone marrow blasts, immune phenotype, $B C R-A B L 1, I K Z F 1$ deletion, risk group, MRD-test result at the end of induction therapy and/or post-remission therapy in multi-variate analyses (Table 2).

\section{CSRP2 transcript levels, CIR and RFS}

Median follow-up was 20 months (range 1-90 months). Complete remission rates after one cycle of induction therapy in subjects with high and low CSRP2 transcript levels were similar (84\% [76, 92\%] vs.
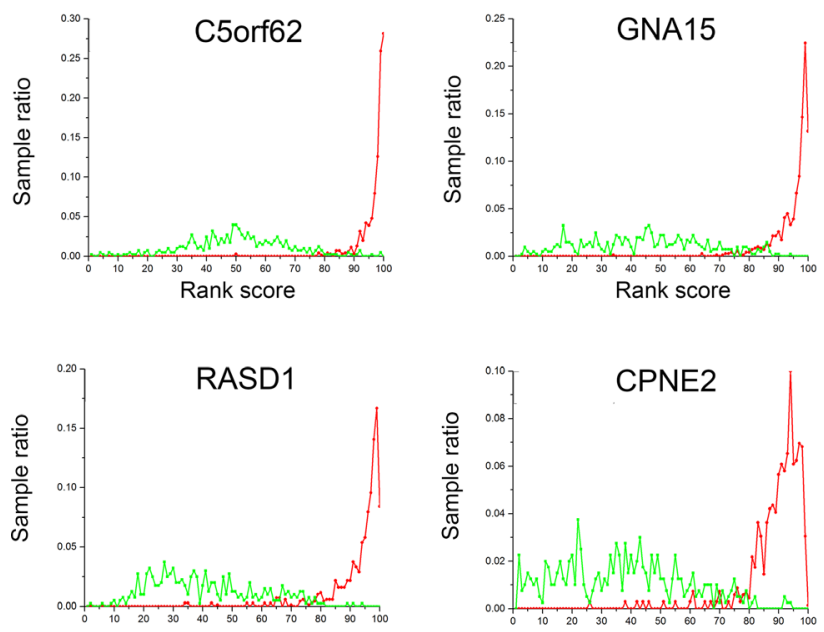

Rank score
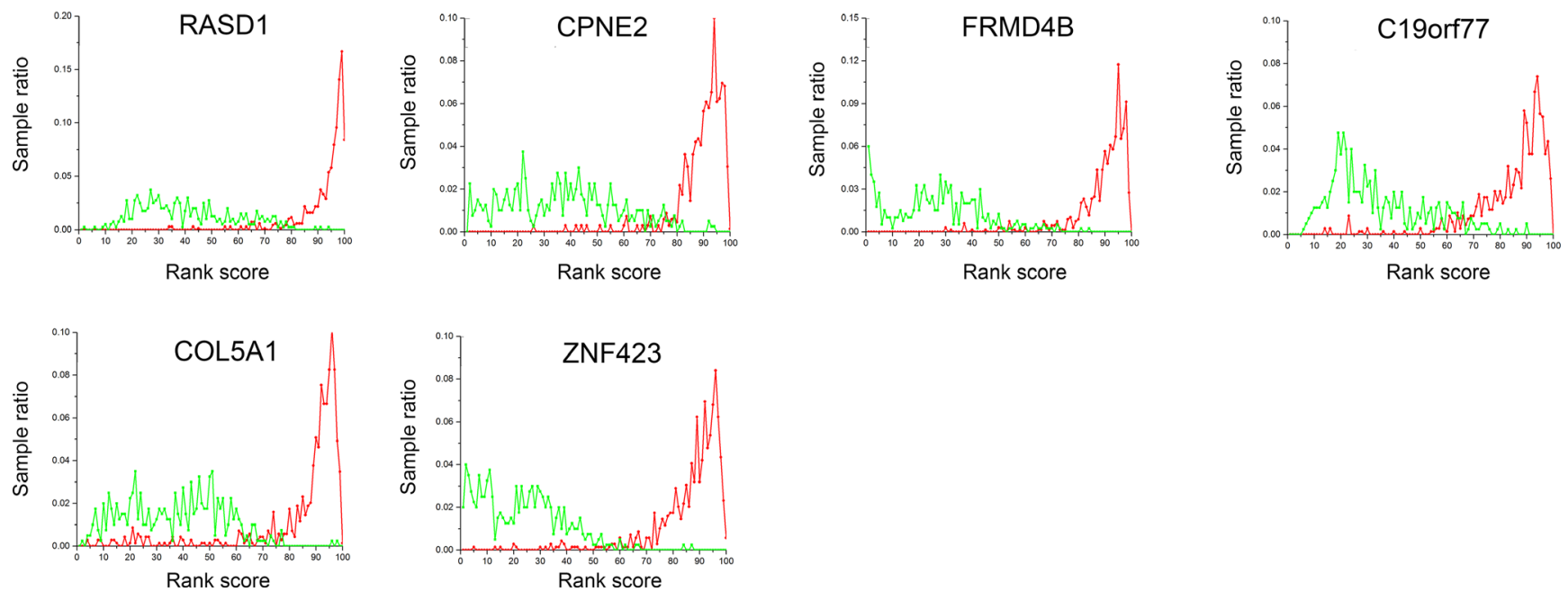

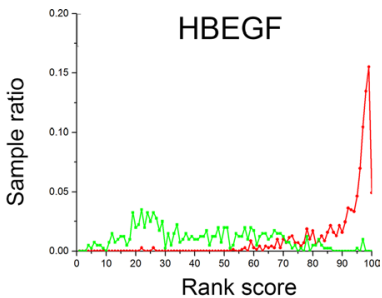

\section{CSRP2 transcript level is independently associated with CIR and RFS in subjects with normal cytogenetics}

We next analyzed the prognostic impact of CSRP2 mRNA expression in the 56 subjects with normal
$88 \%$ [81, 94\%]; $P=0.488)$. Five-year CIR in subjects achieving remission with high CSRP2 transcript levels was significantly higher than in subjects with low CSRP2 transcript levels $(60 \%[58,61 \%]$ vs. 34\% [33, 34\%]; $P=0.043$; Figure 4A). In subjects with low CSRP2 with $39 \%(22,55 \% ; P=0.060)$ in subjects with high CSRP2 transcript levels (Figure 4B). In multivariate analyses including age ( $\geq$ vs. $<35$ years), gender, WBC ( $\geq$ vs. $<30 \times 10 \mathrm{E}+9 / \mathrm{L}), B C R-A B L 1(\mathrm{~N} / \mathrm{Y}), M L L$ (no/yes) or IKZF1 deletion (N/Y), treatment positive) and CSRP2 transcript level (low/high), a negative MRD-test result, female sex, no $M L L$ translocation and chemotherapy/allotransplant were associated with lower CIR (Table 3). Female sex, no MLL translocation and chemotherapy/allotransplant were associated with better RFS (Table 3).
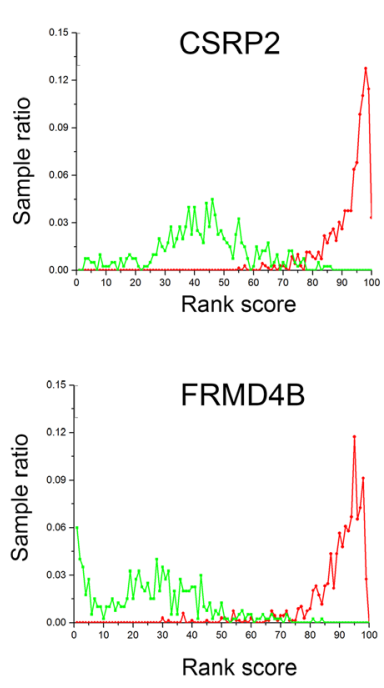

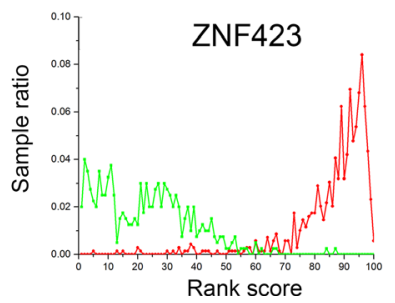

Figure 1: Gene expression profiles of the 9 selected genes. Rank-based gene expression (RBE) curves discussed in the ImmuSort database indicate sample distribution in terms of gene expression across various individuals and experimental conditions. The x-axis represents the percentile rank scores from 1 to 100 with increasing expression intensity. The y-axis represents the sample proportion at an indicated rank score. The right and left peaks indicate high and low expression, respectively. Green lines are B cells from normals and red lines, B-cells from B-cell ALL. ZNF423 is illustrated as a positive control. 
Table 2: Association of CSRP2 transcript levels with the clinical features of adult B-cell ALL

\begin{tabular}{|c|c|c|c|c|}
\hline Variable & $\begin{array}{c}\text { Total } \\
N=168\end{array}$ & $\mathrm{~L}-C S R P 2 N=88$ & H-CSRP2 N=80 & $P$-value \\
\hline Gender & & & & 0.895 \\
\hline Male & 87 & 46 & 41 & \\
\hline Age (years) & & & & 0.275 \\
\hline Median & 33 & 31 & 34 & \\
\hline Range & $14-67$ & $14-55$ & $14-67$ & \\
\hline Age (years) group & & & & 0.469 \\
\hline$<35$ & 91 & 50 & 41 & \\
\hline $\mathrm{WBC}(\times 10 \mathrm{E}+9 / \mathrm{L})$ & & & & 0.056 \\
\hline Median & 10.6 & 8.6 & 15.5 & \\
\hline Range & $0.3-586$ & $0.3-523$ & $1.3-586$ & \\
\hline WBC group $(\times 10 \mathrm{E}+9 / \mathrm{L})$ & & & & 0.037 \\
\hline$<30$ & 116 & 67 & 49 & \\
\hline Platelets $(\times 10 \mathrm{E}+9 / \mathrm{L})$ & & & & 0.483 \\
\hline Median & 58.6 & 60.0 & 48.2 & \\
\hline Range & $0.2-338$ & $0.2-338$ & $4.0-310$ & \\
\hline Bone marrow blasts $(\%)$ & & & & 0.131 \\
\hline Median & 88.0 & 86.5 & 89.0 & \\
\hline Range & 20-99 & $20-99$ & $22-97$ & \\
\hline \multicolumn{5}{|l|}{ Immune phenotype } \\
\hline Common-B-ALL & 141 & 76 & 65 & 0.367 \\
\hline Pre-B-ALL & 9 & 5 & 4 & 1.000 \\
\hline Pro-B-ALL & 18 & 7 & 11 & 0.225 \\
\hline \multicolumn{5}{|l|}{ Cytogenetics } \\
\hline Normal & 56 & 34 & 22 & 0.126 \\
\hline$B C R-A B L 1$ & 56 & 30 & 26 & 0.827 \\
\hline$M L L$-translocation & 11 & 0 & 11 & 0.000 \\
\hline Hypo-diploidy & 1 & 0 & 1 & - \\
\hline Complex cytogenetics & 4 & 3 & 1 & 0.622 \\
\hline Other cytogenetics & 40 & 21 & 18 & 0.834 \\
\hline$I K Z F 1$-deletion & 77 & 37 & 40 & 0.301 \\
\hline Risk-group & & & & 0.141 \\
\hline High-risk & 72 & 33 & 39 & \\
\hline Standard-risk & 96 & 55 & 41 & \\
\hline MRD-test & & & & 0.234 \\
\hline Positive & 97 & 47 & 50 & \\
\hline Chemotherapy-only & 76 & 36 & 40 & 0.237 \\
\hline
\end{tabular}

L-CSRP2, low transcripts.

$\mathrm{H}-C S R P 2$, high transcripts.

cytogenetics. Rates of complete remission after one cycle of induction therapy in subjects with high and low CSRP2 transcript levels were similar $(81 \%[64,98 \%]$ vs. $83 \%$ [70, 95\%]; $P=1.0)$. High CSRP2 transcript levels were associated with a higher 5-year CIR $(56 \%[53,59 \%]$ vs. $19 \%[18,20 \%] ; P=0.011$; Figure $4 \mathrm{C})$ and worse 5 -year RFS (41\% [17, 65\%] vs. $80 \%$ [66-95\%]; $P=0.007$; Figure 4D) compared with subjects with low CSRP2 transcript levels. In multivariate analyses high CSRP2 transcript levels were independently-associated with a greater CIR
$(\mathrm{HR}=5.32[1.64-17.28] ; P=0.005)$ and worse RFS $(\mathrm{HR}=5.56[1.87,16.53] ; P=0.002$; Table 4). Female sex and chemotherapy/allotransplant were also associated with a lower CIR and better RFS (Table 4).

\section{CSRP2 promotes cell proliferation in vitro and in vivo}

To study the biological role of CSRP2 in B-cell ALL we developed 2 B-cell lines: (1) BV173 in which CSRP2 
Table 3: Multivariate analyses of CIR and RFS in adults with B-cell ALL

\begin{tabular}{lcc}
\hline Outcome $^{a}$ & HR $\mathbf{( 9 5 \%} \mathbf{C I})$ & $\boldsymbol{P}$-value \\
\hline CIR & & \\
MRD Positive $v s$. Negative & $1.16(1.04-1.30)$ & 0.010 \\
Female $v s$. male & $0.49(0.28-0.86)$ & 0.012 \\
Transplant: Yes $v s$. No & $0.28(0.17-0.46)$ & 0.000 \\
MLL translocation: Yes $v s$. No & $3.83(1.64-8.91)$ & 0.002 \\
RFS & & \\
Female $v s$. male & $0.45(0.26-0.76)$ & 0.003 \\
Transplant: Yes $v s$. No & $0.24(0.14-0.41)$ & 0.000 \\
MLL translocation: Yes $v s$. No & $3.86(1.61-9.28)$ & 0.003 \\
\hline
\end{tabular}

Abbreviations: HR, hazard ratio; CI, confidence interval.

${ }^{a}$ Other variables with $P>0.1$ (including High vs. low CSRP2) were sequentially excluded from the model.

was stably knocked-down (CSRP2-KD); and (2) a CSRP2overexpressing Ramos cell line (CSRP2-OE; Figure 5A). Proliferation was significantly decreased in CSRP2-KD BV173 cells compared with cells transfected with control lentiviral particles. In contrast, CSRP2-over-expression in CSRP2-OE markedly- increased proliferation (Figure 5B).

We also tested whether CSRP2 expression promoted colony formation. Silencing of CSRP2 expression significantly decreased numbers of colony-forming units compared with controls. CSRP2 over-expression had the converse effect (Figure 5C).

To further study the in vivo oncogenic activity of CSRP2 unmodified Ramos cells and CSRP2-OE Ramos cells were injected subcutaneously into the dorsal right flank of nude mice. Tumors induced by CSRP2-OE Ramos cells were significantly larger than tumors induced by control Ramos cells $(P<0.01$; Figure 5D). These data indicate CSRP2 increases the oncogenicity of neoplastic B-cell lines in vitro and in vivo.

\section{CSRP2 promotes cell-cycle progression and cell migration}

Data from flow cytometry analyses showed increased CSRP2 expression promote cell-cycle progression: CSRP2-OE cells in $\mathrm{S}$ and $\mathrm{G} 2 / \mathrm{M}$ phases increased substantially compared with control cells whereas CSRP2-KD BV173 cells accumulated in G0/ G1 phases compared with control cells (Figure 6A). Bio-informatic analyses showed CSRP2 high expressing cells had increased cell-cycle progression (Table 5). CSRP2 was moderately expressed in normal human
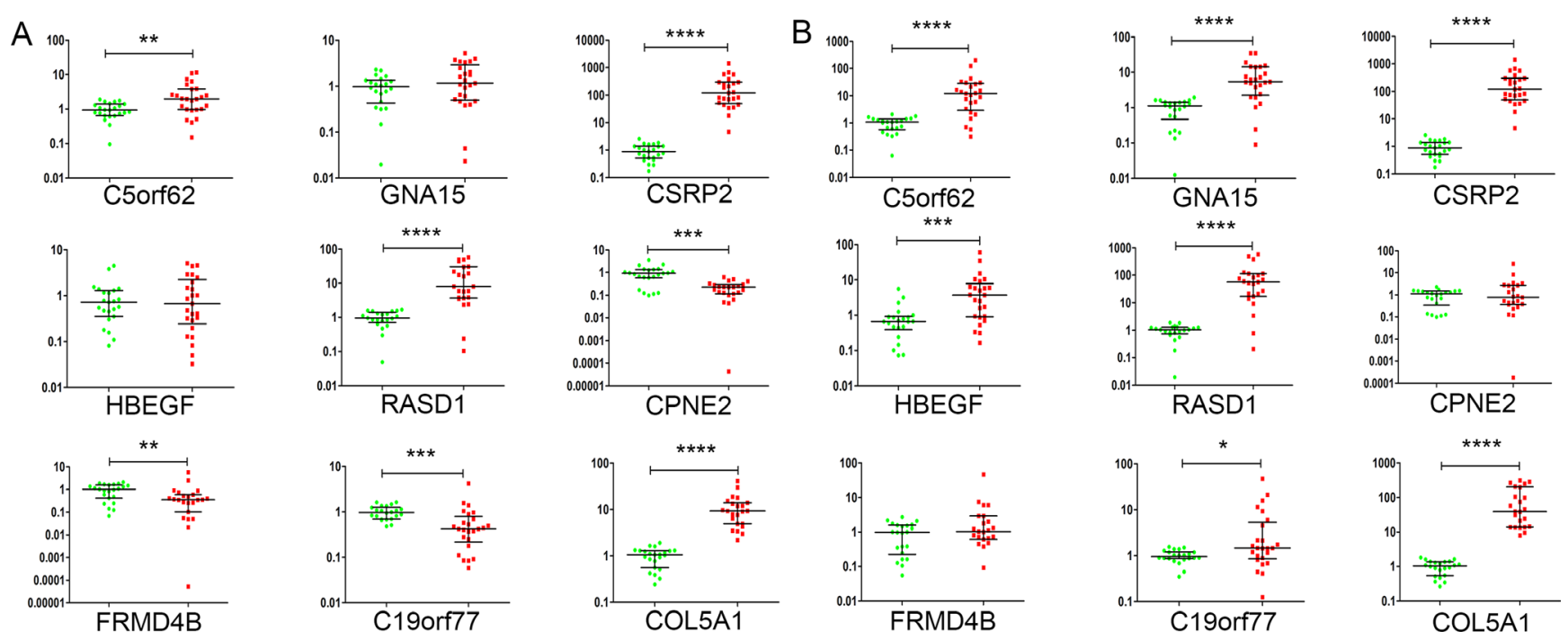

Figure 2: Validation of the 9 selected genes by RT-qPCR. (A) Transcript levels with $A B L 1$ as the internal control. (B) Transcript levels with $G A P D H$ as the internal control. The y-axis represents relative transcript level of genes. Green dots are normal bone marrow samples and red dots, adults with B-cell ALL. Bars represent median and quartiles value. $* P<0.05 ; * * P<0.01 ; * * * P<0.001$; $* * * * P<0.0001$. 
Table 4: Multivariate analyses of CIR and RFS in adult B-cell ALL with normal cytogenetics

\begin{tabular}{lll}
\hline Outcome $^{a}$ & HR (95\%CI) & P-value \\
\hline CIR & $5.32(1.64-17.28)$ & 0.005 \\
High vs. low CSRP2 & $0.13(0.03-0.67)$ & 0.014 \\
Female vs. male & $0.32(0.14-0.74)$ & 0.008 \\
Transplant Yes vs. No & $2.23(0.96-5.16)$ & 0.061 \\
IKZF1 deleted Yes vs. No & & \\
RFS & $5.56(1.87-16.53)$ & 0.002 \\
High $v$ s. low CSRP2 & $0.14(0.03-0.64)$ & 0.011 \\
Female vs. male & $0.33(0.12-0.90)$ & 0.030 \\
Transplant Yes $v s$. No &
\end{tabular}

Abbreviations: HR, hazard ratio; CI, confidence interval.

${ }^{a}$ Other variables with $P>0.1$ were sequentially excluded from the model.
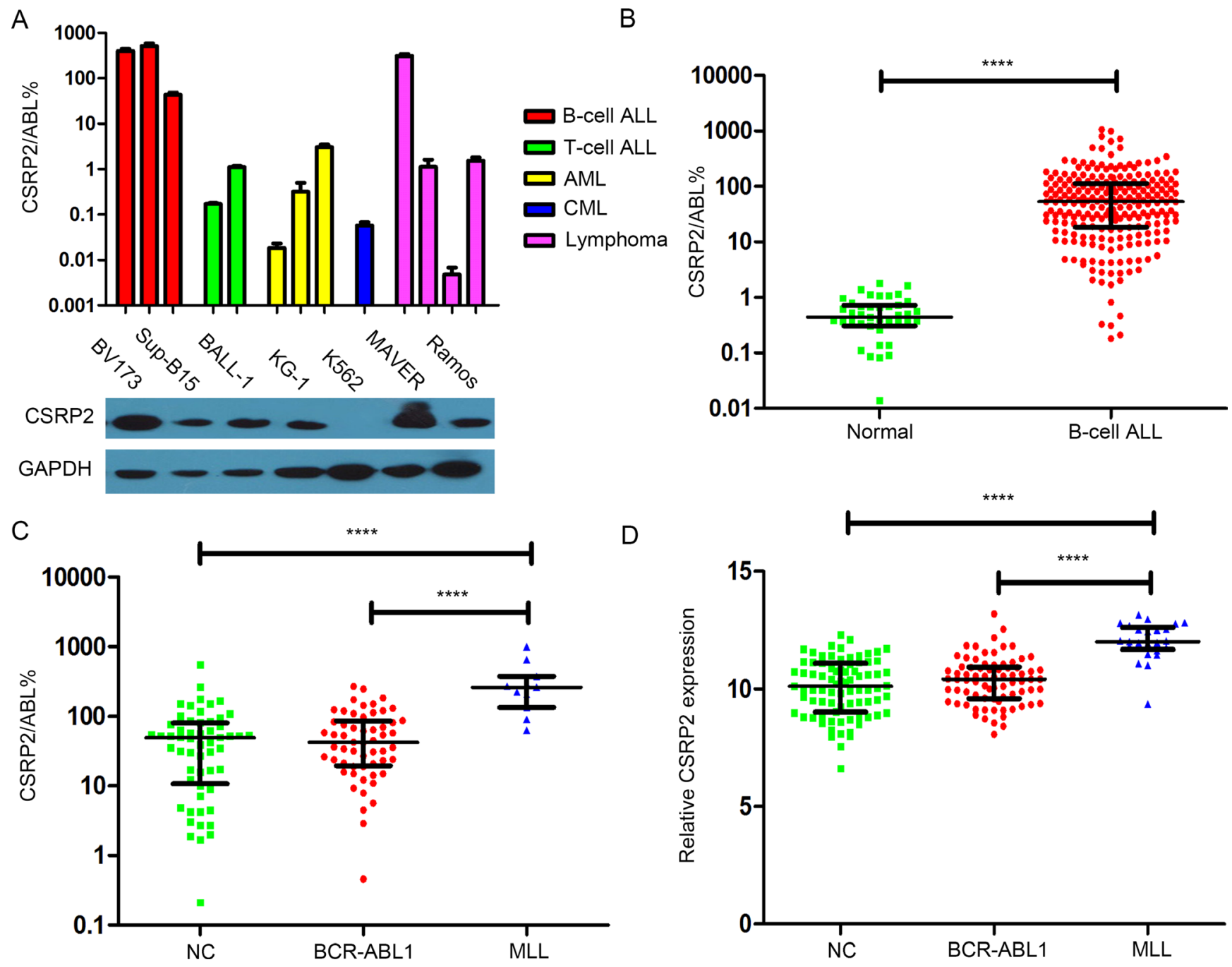

Figure 3: CSRP2 transcript level. CSRP2 expression in (A) Leukemia and lymphoma cell lines (up: RT-qPCR; down: western blot); (B) Normal bone marrow and adults with B-cell ALL; (C) Different karyotypes of adults with B-cell ALL; (D) Different karyotypes of adults with B-cell ALL from the data set of GSE34861. Bars represent median and quartiles value. NC, normal cytogenetics. $* * * * P<0.0001$. 
Table 5: Functional annotation of CSRP2 high expression B-cells

\begin{tabular}{|c|c|c|c|c|}
\hline Term & Name & $P$-value & Fold-enrichment & $\begin{array}{c}\text { Adjusted } P \text {-value } \\
\text { (Bonferroni) }\end{array}$ \\
\hline GO:0000279 & M-phase & $1.46 \mathrm{E}-07$ & 7.32 & $1.21 \mathrm{E}-04$ \\
\hline GO:0007067 & Mitosis & $2.35 \mathrm{E}-07$ & 9.27 & $1.96 \mathrm{E}-04$ \\
\hline GO:0000280 & Nuclear division & $2.35 \mathrm{E}-07$ & 9.27 & $1.96 \mathrm{E}-04$ \\
\hline GO:0022403 & Cell-cycle phase & $2.35 \mathrm{E}-07$ & 6.27 & $1.96 \mathrm{E}-04$ \\
\hline GO:0000087 & $\begin{array}{l}\text { M-phase of mitotic } \\
\text { cell cycle }\end{array}$ & $2.77 \mathrm{E}-07$ & 9.10 & $2.31 \mathrm{E}-04$ \\
\hline GO:0048285 & Organelle fission & $3.40 \mathrm{E}-07$ & 8.90 & $2.84 \mathrm{E}-04$ \\
\hline GO:0000278 & Mitotic cell-cycle & $5.14 \mathrm{E}-07$ & 6.51 & 4.29E-04 \\
\hline GO:0007049 & Cell-cycle & $2.35 \mathrm{E}-06$ & 4.06 & $1.96 \mathrm{E}-03$ \\
\hline GO:0007059 & $\begin{array}{l}\text { Chromosome } \\
\text { segregation }\end{array}$ & $4.36 \mathrm{E}-06$ & 16.01 & $3.63 \mathrm{E}-03$ \\
\hline GO:0022402 & Cell-cycle process & $7.54 \mathrm{E}-06$ & 4.59 & $6.27 \mathrm{E}-03$ \\
\hline GO:0051726 & $\begin{array}{l}\text { Regulation of cell- } \\
\text { cycle }\end{array}$ & $6.18 \mathrm{E}-05$ & 5.60 & $5.03 \mathrm{E}-02$ \\
\hline
\end{tabular}

The annotations are from biological processes of Gene Ontology (GO) via the DAVID website (https://david.ncifcrf.gov).
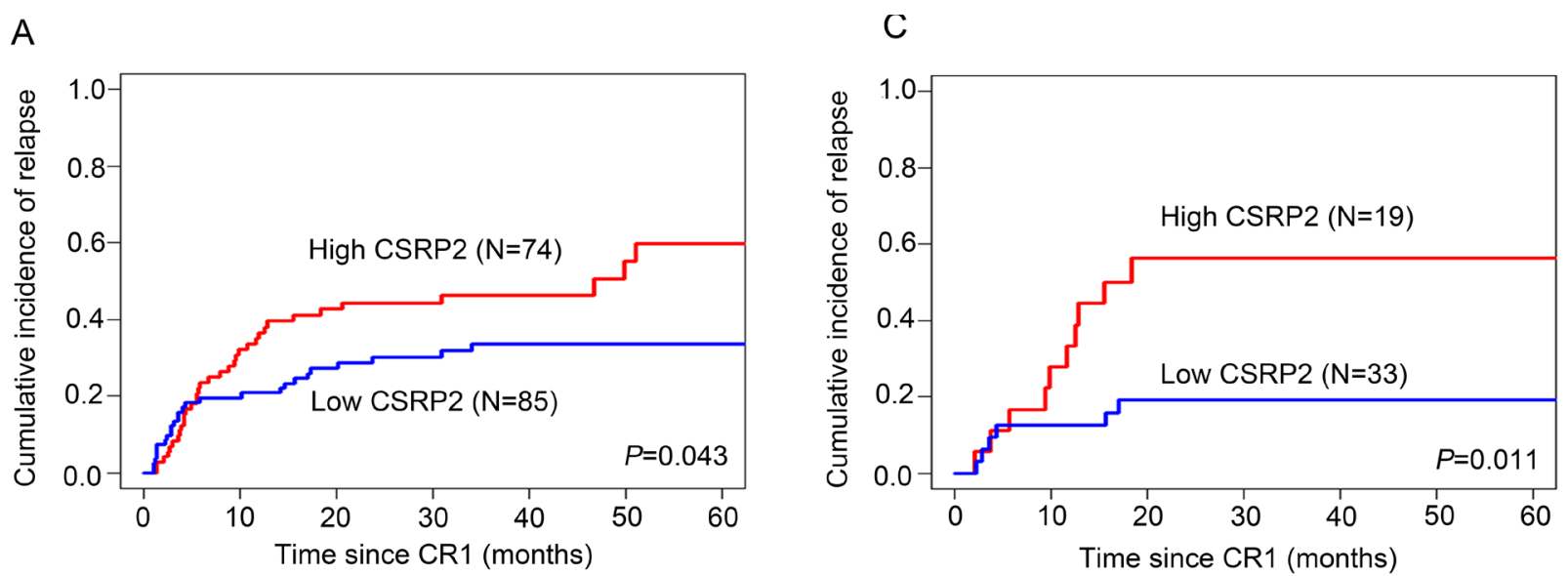

B
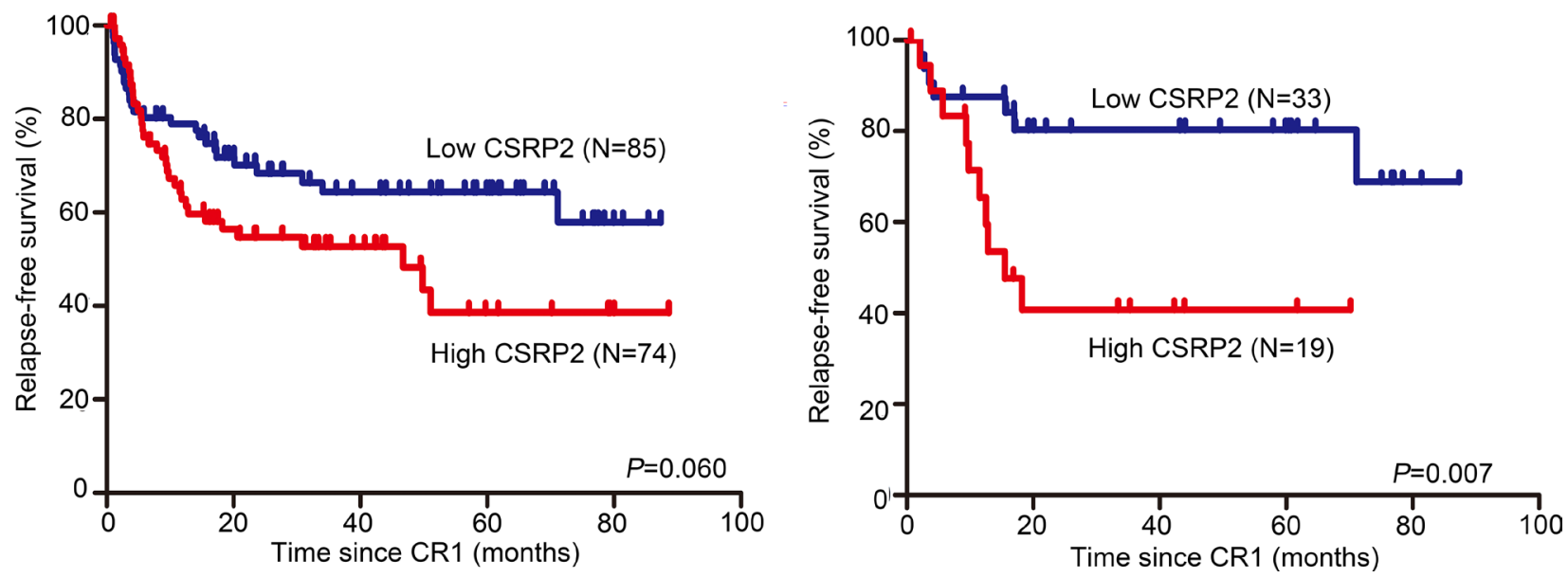

Figure 4: Association of CSRP2 with CIR and RFS. (A) Cumulative incidence of relapse (CIR); and (B) relapse-free survival (RFS) were compared between subjects with high or low CSRP2 transcript levels. (C) CIR; (D) RFS were compared between subjects with normal cytogenetics with high or low CSRP2 transcript levels. 
B-cells (ARS = 43.16). In our previous study we reported moderately expressed genes had more plastic or variable expression in diverse experimental conditions [31]. The gene plastic (GPL) score of CSRP2 was 19 in normal B-cells (400 GSMs) making it suitable for virtual sorting,

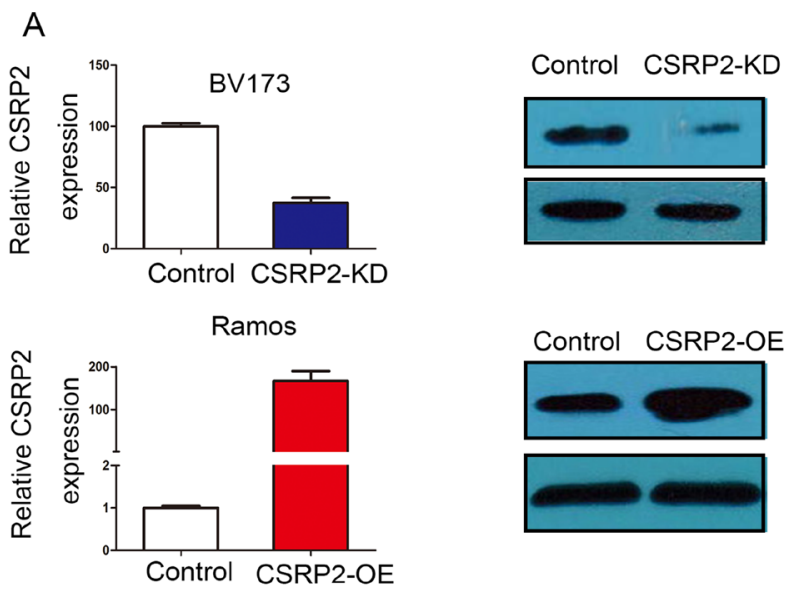

C
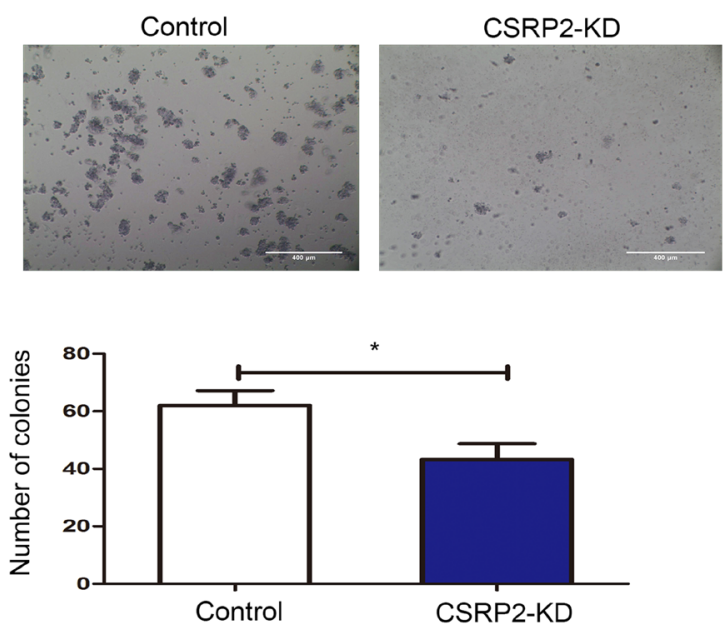

D

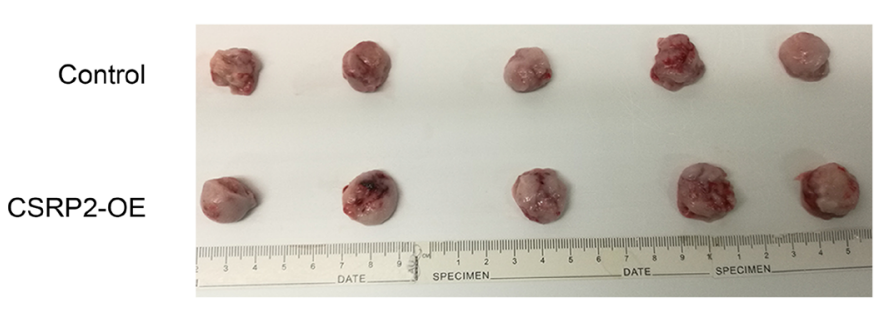

an immune informatics method to evaluate immune cell subpopulations and their functions based on highly plastic genes.

Migration activity of CSRP2-OE Ramos cells was greater than that of control Ramos cells. Knockdown

B
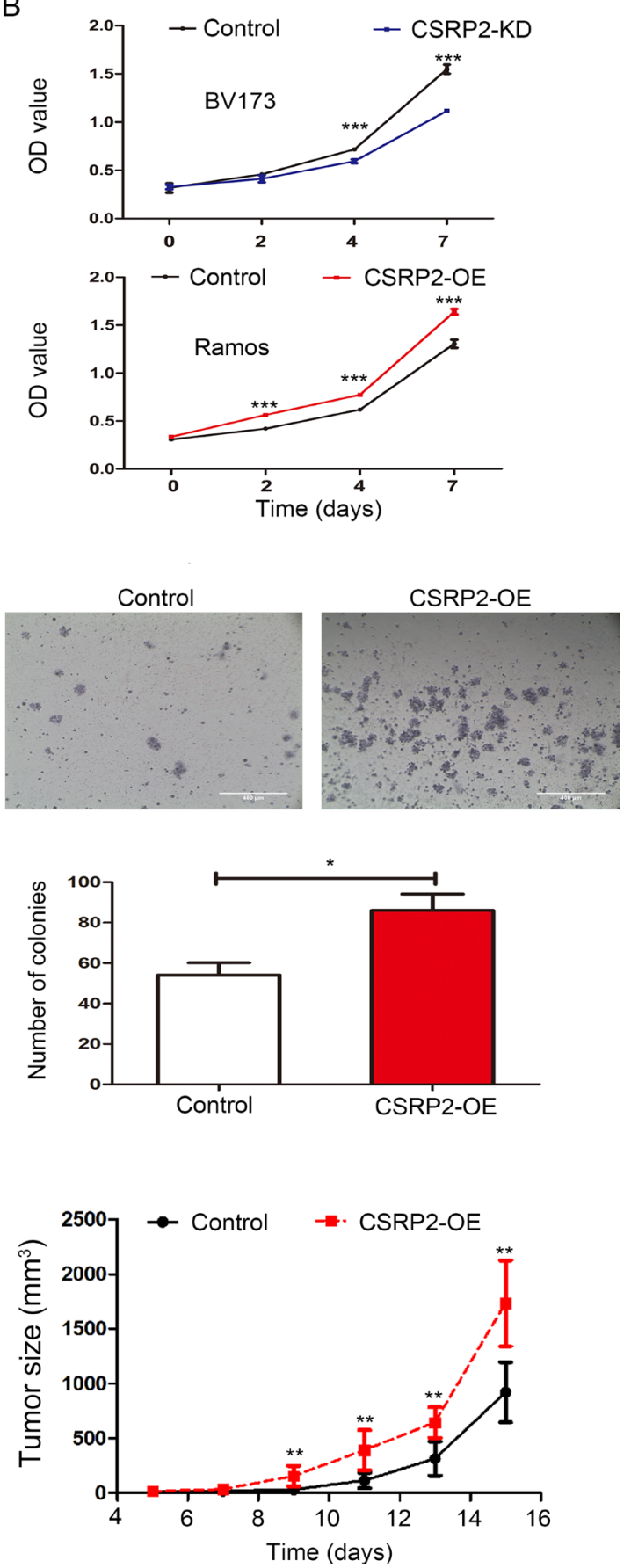

Figure 5: CSRP2 promotes cell proliferation in vitro and in vivo. (A) Knockdown efficiency of CSRP2 in BV173 cells and ectopic expression of CSRP2 in Ramos cells were demonstrated by RT-qPCR and western blot; (B) Knockdown of CSRP2 significantly inhibited cell viability in BV173 and ectopic expression of CSRP2 significantly enhanced cell viability in Ramos; (C) Numbers of colonies decreased when transfected with shCSRP2 in BV173 and ectopic expression of CSRP2 increased numbers of colonies in Ramos; Size bar, $400 \mu \mathrm{m}$; (D) A representative picture of tumor formation in nude mice subcutaneously inoculated with CSRP2-OE Ramos cells or control Ramos cells (left panel); Tumor growth curves of CSRP2-OE Ramos cells and control Ramos cells in nude mice (Right panel). Values are mean \pm standard deviation (SD). $* P<0.05 ; * * P<0.01 ; * * * P<0.001$. 
CSRP2 expression in BV173 cells eliminated their migration (Figure 6B).

\section{Subcellular localization of CSRP2 in neoplastic B-cells}

We used cell fractionation analyses to assess subcellular localization of CSRP2 in neoplastic B-cells. CSRP2 protein was detected in the cytoplasm (C) and nucleus $(\mathrm{N})$ and was more intense in the latter (Figure 7A). Silencing CSRP2 slightly decreased nuclear CSRP2 localization in BV173 cells whereas overexpression slightly increased nuclear localization in Ramos cells (Figure 7B).
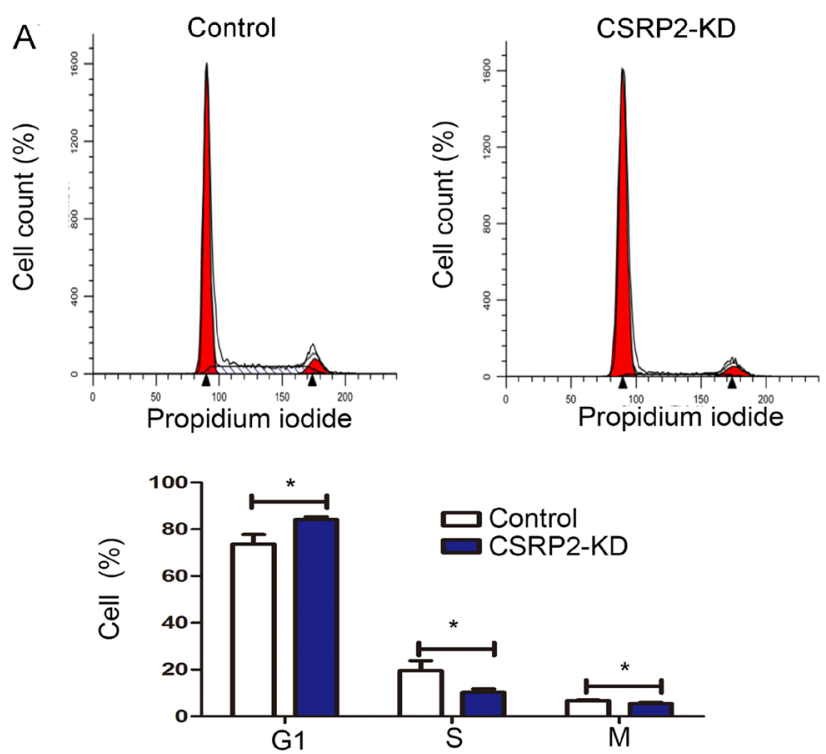

B
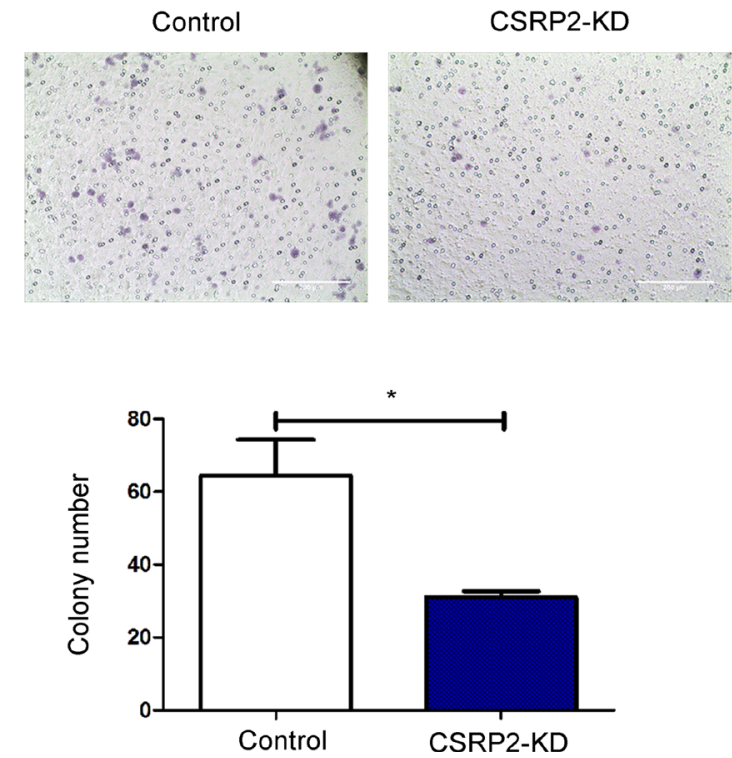

\section{CSRP2 knock-down increases drug-sensitivity}

Drug resistance is the main reason for treatmentfailure and relapse in B-cell ALL. We studied the relationship between CSRP2 transcript levels and B-cell ALL sensitivity to dexamethasone, methotrexate, daunorubicin, cytarabine and imatinib (in BV173 with BCR-ABL1). CSRP2-KD BV173 cells showed increased sensitivity to dexamethasone, methotrexate, daunorubicin and imatinib compared with controls (Figure 8A) whereas CSRP2-OE Ramos cells showed increased resistance to these drugs compared with controls (Figure 8B). These data suggest down-regulation of CSRP2 may improve therapy-outcomes in adult B-cell ALL.
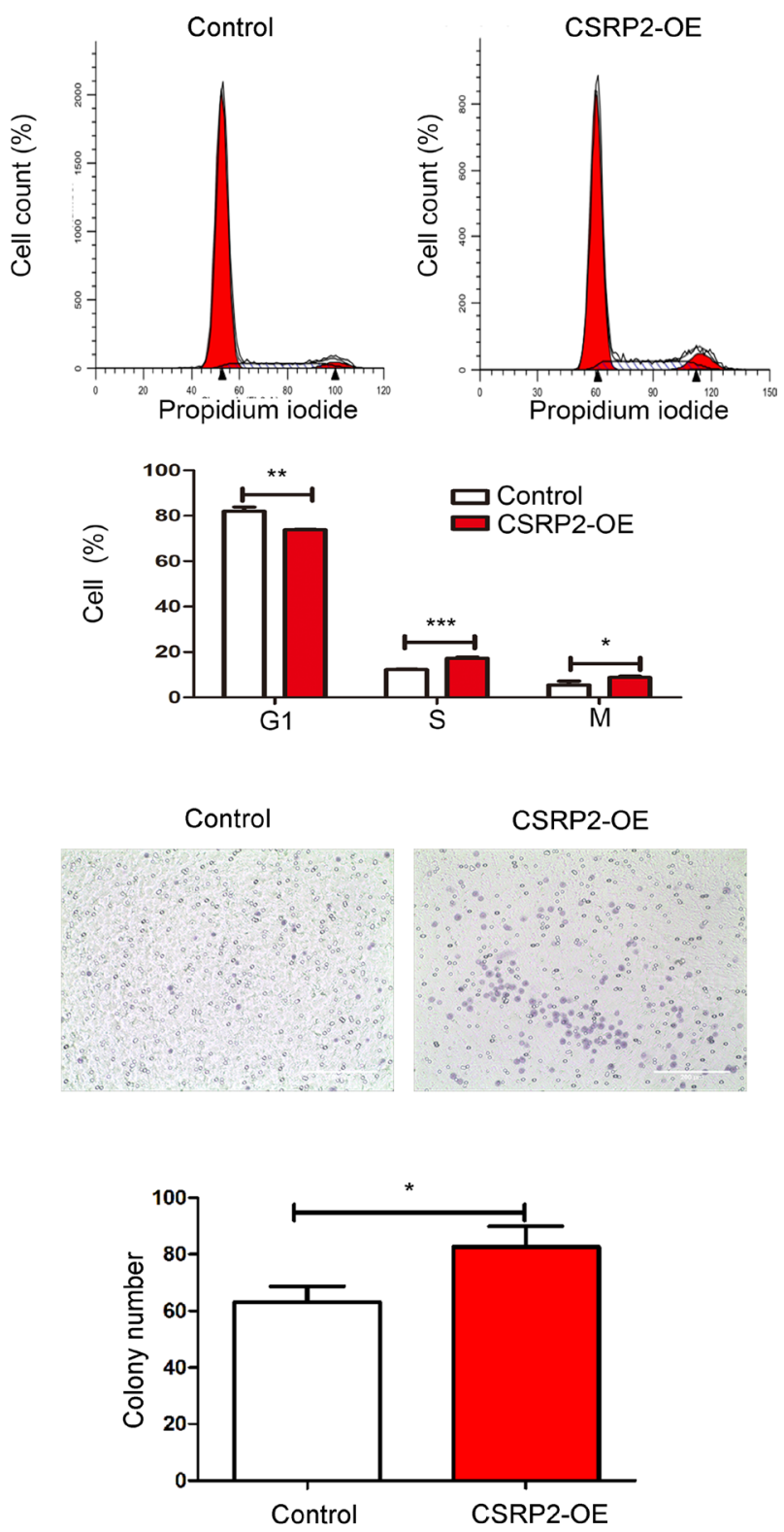

Figure 6: CSRP2 promotes cell-cycle progression and cell migration. (A) Cell cycle distribution was determined by flow cytometry; (B) Knockdown of CSRP2 significantly inhibited cell migration of BV173 cells whereas ectopic expression of CSRP2 significantly increased migration of Ramos cells. Size bar, $200 \mu \mathrm{m}$. Values are mean \pm SD. $* P<0.05 ; * * P<0.01 ; * * * P<0.001$. 


\section{DISCUSSION}

We used bioinformatics-based analyses to identify potentially important genes transcribed in B-cell ALL. We focused on CSRP2 because it was the most differentially expressed gene in our studies. CSRP2 is a possible oncogene in hepatocellular carcinoma and breast cancer $[17,18]$. CSRP1 belongs to the CSRP family and is considered a tumor suppressor gene in hepatocellular carcinoma and colorectal cancer [32, 33] but a possible oncogene in gastric cancer [34]. In this study, we found CSRP2 transcripts were uniformly low in bone marrow mononuclear cells from normals whereas transcript levels were high in cells from adults with newly-diagnosed B-cell ALL.

An in silico analyses using publicly available gene expression datasets reported worse survival of women with the basal-like subtype of breast cancer with high expression of CSRP2 [18]. Our analyses of the prognostic impact of CSRP2 transcript levels on CIR and RFS in adults with B-cell ALL was complex because of confounding with other prognostic variables and therapies. We used multivariate analyses to help resolve this complexity. CIR and RFS of subjects receiving transplants from different donors were similar so these data were combined. We found a positive MRD-test at the end of induction therapy, male sex, $M L L$ translocation and chemotherapy-only were independently-associated with a higher CIR and worse RFS whereas other variables including age, WBC, $B C R-A B L 1, I K Z F 1$ deletion and CSRP2 transcript levels were not. We discuss lack of a significant association between $B C R-A B L 1$ and CIR and RFS previously [35]. Although high CSRP2 mRNA expression was associated with CIR in univariate analyses this association was not significant in multivariate analyses possibly reflecting confounding by high levels
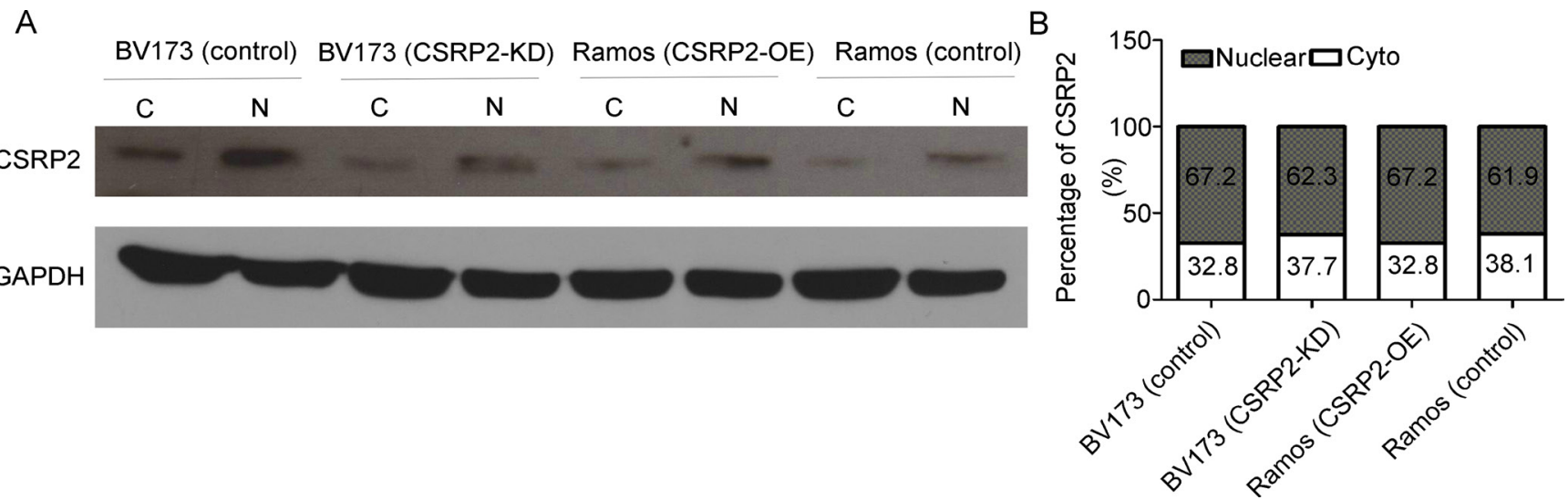

Figure 7: Subcellular localization of CSRP2 in neoplastic B-cells. (A) Representative picture of immunoblots containing subcellular fractions; (B) Percent cytoplasmic and nuclear CSRP2 localizations were determined as follows: cytoplasmic CSRP2 density/ (cytoplasmic CSRP2 density + nuclear CSRP2 density) $\times 100$ and nuclear CSRP2 density/(cytoplasmic CSRP2 density + nuclear CSRP2 density) $\times 100$, respectively.
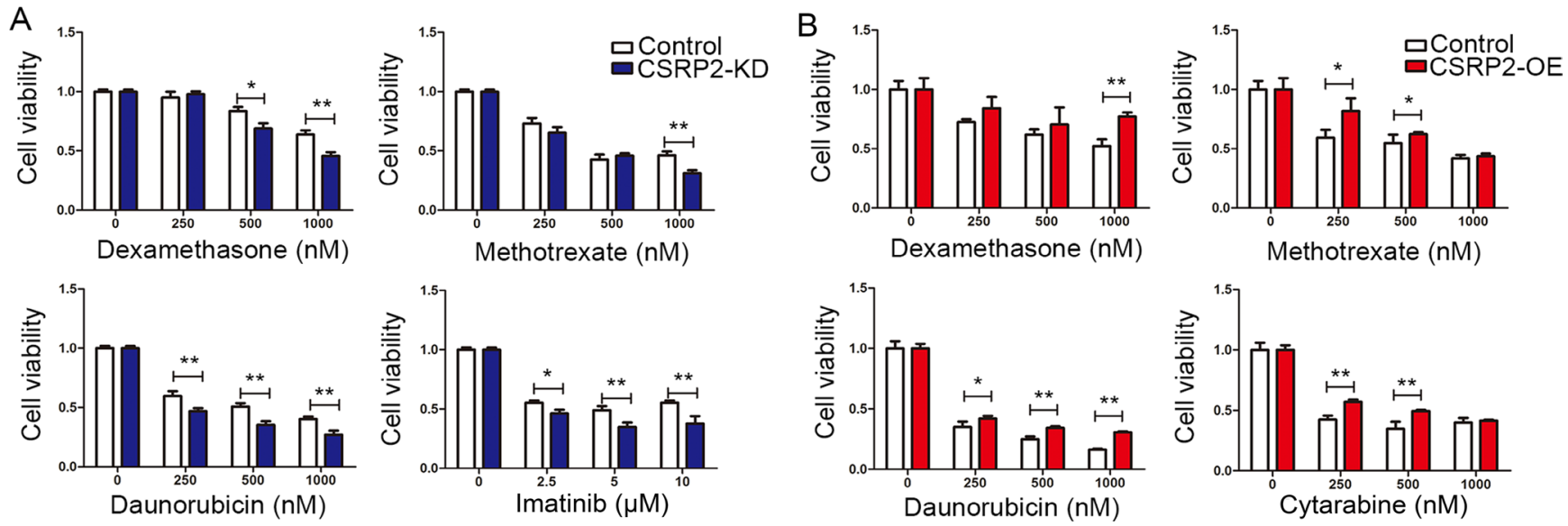

Figure 8: CSPR2 knock-down increases drug sensitivity. (A) Knockdown of CSRP2 in BV173 cells significantly increased sensitivity to dexamethasone, methotrexate, daunorubicin and imatinib; (B) Ectopic expression of CSRP2 in Ramos significantly increased resistance to dexamethasone, methotrexate, daunorubicin and cytarabine. Values are mean $\pm \mathrm{SD}$. ${ }^{*} P<0.05 ;{ }^{*} P<0.01 ; * * * P<0.001$. 
of CSRP2 expression in persons with $M L L$ translocation. Consequently, we re-analyzed an association between CSRP2 transcript levels, CIR and RFS in subjects with normal cytogenetics. In multivariate regression analyses high levels of CSRP2 transcripts were independentlyassociated with a higher CIR and worse RFS regardless of post-remission therapy.

In several experimental models of B-cell ALL increased CSRP 2 transcription promotes cell proliferation, migration and cell-cycle progression, a finding concordant with our bio-informatic analyses. Increased CSRP2 transcription also promotes migration of breast cancer cells via an actin bundling factor [18]. In our study CSRP2 was found predominantly in the nucleus. This contrasts with the cytoskeletal localization reported in breast cancer cells [18]. Moreover, knockdown of CSRP2 transcription increased drug-sensitivity whereas increased CSRP2 transcription increased drug resistance. These data suggest down-regulating CSRP2 transcription might decrease drug resistance and thereby decrease CIR and improve RFS. These conclusions are preliminary but warrant consideration.

There are several limitations to our study which was retrospective and susceptible to selection biases. The cohort with normal cytogenetics was not pre-specified and had relatively few subjects. Also, there is the potential for an interaction between CSRP2 transcript levels and type of post-remission therapy. Because of these limitations our conclusion need validation in a larger, independent prospective cohort. If validated, determination of CSRP2 transcript levels in adult B-cell ALL with normal cytogenetics might inform therapy-decisions. Also, consideration could be given to down-regulating CSRP2 expression as a way to reverse drug resistance.

\section{MATERIALS AND METHODS}

\section{Bioinformatics analyses}

To identify possible B-cell ALL relevant genes data from the ImmuSort database dataset related to B-cell ALL and normal B-cell samples was updated and re-analyzed [9]. This database included gene expression profiles from $>20,000$ genes in human and mouse immune cells based on micro-array platform. Differences (delta values) in average rank score (ARS) were transformed from expressional signal value reflecting gene expression intensity. These data were used for gene expression comparison [9]. When a gene had multiple probe sets the probe with the maximum ARS was used.

\section{Cell lines}

The human B-cell ALL cell lines BV173, Sup-B15 and BALL-1 were obtained from Guangzhou Jennio Biotech Co. Ltd (Guangzhou, China). The human
Burkitt lymphoma cell line Ramos was a kind gift from Professor H.S. Zhao (Peking University Health Science Center, Beijing, China). The human T-cell ALL cell lines 6T-CEM and MOLT4, the human AML cell lines KG-1, NB4 and HL60, the human chronic myelogenous leukemia cell line K562 and the human lymphoma cell lines MAVER, U937, Raji and MOLP2 were available in our laboratory. Cell lines were cultured in Roswell Park Memorial Institute (RPMI) 1640 medium (Gibco, Billings, MT, USA) containing 10\% fetal bovine serum (Gibco), penicillin (100 U/ml, Gibco) and streptomycin $(100 \mu \mathrm{g} /$ $\mathrm{ml}$, Gibco). Cells were grown at $37^{\circ} \mathrm{C}$ in a humidified $5 \%$ $\mathrm{CO} 2$ atmosphere.

\section{Subjects}

Bone marrow samples were obtained from adults with B-cell ALL $(N=236)$ and normals $(N=43)$ at the Hematology Department of Peking University People's Hospital, Beijing, China and CSRP2 transcript levels assessed. Complete clinical and laboratory data were available for 168 subjects enrolled December, 2008 to June, 2014. Subjects were followed until death, loss to follow-up or June, 2016. The study was approved by the Ethics Committee of Peking University People's Hospital and informed consent was obtained according to the Declaration of Helsinki. Details of treatment regimens are reported [35]. 92 subjects (55\%) received an allotransplant, 28 from an HLA-identical sibling, 1 from an HLA-matched-unrelated donor and 63 from HLAhaplotype-matched related donors [36, 37]. Complete remission, refractory disease, relapse and risk-stratification were defined as described [2]. Relapse-free survival (RFS) was determined from the date of first complete remission to the date of first relapse. Cumulative incidence of relapse (CIR) was determined from the date of first complete remission to the date of first relapse or death in complete remission.

\section{Immune phenotype, measureable residual disease (MRD) and cytogenetic analyses}

Bone marrow samples were analyzed using standard four-color flow cytometry (FCM) [38]. Immune phenotypes were identified as: (1) early precursor B-cell ALL (pro-B-ALL) for CD10-negative, CD19-postive, cCD79a-postive, cCD22 positive and TdT-positive; (2) common B-cell ALL (common-B-ALL) for CD10-postive; and (3) precursor B-cell ALL (pre-B-ALL) for cytoplasmic $\mu+$, sIg-, CD10+/- [2]. MRD was quantified by analyzing leukemia-associated aberrant immune phenotypes (LAIPs) using four-color flow cytometry as described [39]. A positive MRD-test was defined as $\geq 0.1 \%$ of cells with an LAIP phenotype in $\geq 1$ bone marrow samples. Cytogenetic analyses were performed by G-banding [40]. BCR-ABL1 transcripts and $M L L$ rearrangements were detected 
with quantitative real-time polymerase chain reaction (RT-qPCR) [41, 42]. IKZF1 deletions were detected as described [35].

\section{Lentiviral transduction}

BV173 cells were infected with human CSRP2 shRNA lentiviral particles (Santa Cruz Biotechnology, Santa Cruz, CA) or blank control lentiviral particles (Santa Cruz) at a 100 multiplicity of infection (MOI). Media containing lentiviral particles were replaced with complete medium $12 \mathrm{~h}$ post-infection and stably transfected BV173 cells were selected with $0.5 \mu \mathrm{g} / \mathrm{ml}$ puromycin dihydrochloride (Genechem, Shanghai, China) at $96 \mathrm{~h}$ post-infection. Ramos cells were infected with human CSRP2 lentiviral activation particles (Santa Cruz) or control lentiviral activation particles (Santa Cruz) at a 100 MOI. Stably transfected Ramos cells were selected with $2.5 \mu \mathrm{g} / \mathrm{ml}$ puromycin dihydrochloride (Genechem), $15 \mu \mathrm{g} / \mathrm{ml}$ Blasticidin S HCl ${ }^{\mathrm{TM}}$ (Solarbio, Beijing, China) and $2000 \mu \mathrm{g} / \mathrm{ml}$ Hygromycin $\mathrm{B}^{\mathrm{TM}}$ (Solarbio). CSRP2 expression levels were confirmed by RT-qPCR and western blot analyses.

\section{RNA preparation and RT-qPCR}

Mononuclear cells were isolated from bone marrow samples by Ficoll-Hypaque ${ }^{\mathrm{TM}}$ density gradient centrifugation and RNA extracted using the TRIzol ${ }^{\mathrm{TM}}$ technique (Invitrogen, Carlsbad, CA, USA) according to the manufacturer's instructions and cDNA synthesized as described [43]. mRNA expression levels were analyzed using SYBR ${ }^{\circledR}$ green (Applied Biosystems, Foster City, CA, USA) to validate differential expression screened out by bioinformatics analyses with $A B L 1$ or GAPDH as internal controls [44]. Gene transcript levels were determined using the $2^{-\Delta \Delta \mathrm{Ct}}$ method. Average gene transcript levels in bone marrow samples from normals were used as calibrator. Other mRNA levels were determined by the TaqMan ${ }^{\circledR}$ method [45]. CSRP2 transcript levels were normalized to $A B L 1$ expression as recommended by the Europe Against Cancer group [46]. Copy numbers of CSRP2 and ABL1 were calculated from standard curves using the $\mathrm{Ct}$ values. Samples were assayed in duplicate to evaluate data reproducibility and average threshold $\mathrm{Ct}$ values calculated for expression analyses. Serial dilutions of plasmids expressing $A B L 1$ and CSRP2-positive bone marrow specimens were amplified to construct standard quantification curves [41]. These curves indicated similar amplification efficiency for $A B L 1$ and CSRP2 with slopes of -3.50 and -3.49 . Detection sensitivity was approximately 1-10 copies in the plasmid DNA standards and 10E5 in CSRP2-positive bone marrow samples. For each measurement the curve threshold amplification was set at 0.08 for $A B L 1$ and $C S R P 2$. Primers and probe sequences are shown in Supplementary Table 2.

\section{Western blot analyses}

Western blotting was done as described [47]. Cytoplasmic and nuclear fractions were extracted as described [48]. The first antibodies were anti-CSRP2 (rabbit monoclonal, 1:1000; Abcum, Cambridge, UK) and anti-GAPDH (rabbit monoclonal, 1:1000; Cell Signaling, Danvers, MA, USA) and the second antibody, horseradish peroxidase-conjugated goat anti-rabbit IgG (1:10000; Santa Cruz Biotechnology, Santa Cruz, CA, USA).

\section{Cell-cycle analyses}

Cells were seeded to 6-well plates and starved by adding serum-free medium for G1 synchronization. After 24 hours, medium containing 10\% fetal bovine serum was added for an additional 48 hours. Cells were fixed in $75 \%$ ethanol, stained with propidium iodide (BD Pharmingen, San Jose, CA, USA) and analyzed by flow cytometry. Results were analyzed with ModFit LT2.0 software (Coulter Electronics, Hialeah, FL, USA).

\section{Cell proliferation and viability assay}

Cell proliferation was determined with the Cell Counting Kit-8 (CCK8, Dojin Laboratories, Kumamoto, Japan) assay. Briefly, $4 \times 10 \mathrm{E}+4$ cells were seeded into each well of 96-well plates. 2, 4 or $7 \mathrm{~d}$ later $10 \mu \mathrm{l}$ of the kit reagent was added to each well and $2 \mathrm{~h}$ later all plates were scanned by a microplate reader at $450 \mathrm{~nm}$. CCK8 was also used to determine cell viability after drug exposures including daunorubicin, dexamethasone, methotrexate, cytarabine and imatinib (Solarbio, Beijing, China). Cells were seeded and $72 \mathrm{~h}$ later $10 \mu \mathrm{l}$ of the kit reagent was added to each well and $2 \mathrm{~h}$ later plates were scanned by a microplate reader at $450 \mathrm{~nm}$. Cell viability was assessed based on the value of fluorescent signal of live cells with no drug treatment. Experiments were performed in triplicate for 3 times independently.

\section{Colony formation assays}

Cells were suspended in $1 \mathrm{~mL}$ of complete MethoCult ${ }^{\mathrm{TM}}$ medium and plated in 6 well plates at a concentration of $4 \times 10 \mathrm{E}+3 /$ well. Colonies were maintained at $37^{\circ} \mathrm{C}$ with $5 \% \mathrm{CO} 2$ and $95 \%$ humidity for $7 \mathrm{~d}$ and then counted and scored at day 7 after staining with $1 \%$ crystal violet (Sigma, St. Louis, MO, USA). Only colonies of $\geq 50$ cells were scored. Assays were done in triplicate for 3 times independently.

\section{Cell migration assay}

Cells were seeded into the upper chamber of a Transwell insert (pore size, $8 \mu \mathrm{m}$ ) in RPMI-1640 supplemented with $1 \%$ FBS. The upper chamber was then 
placed into the Transwell containing medium with $10 \%$ FBS in the lower chamber. After $24 \mathrm{~h}$, cells remaining in the lower surface of the insert were stained with crystal violet. Experiments were conducted in triplicate for 3 times independently.

\section{Tumor xenograft mouse model}

Male athymic 6-week-old Balb/c nude mice (Beijing HFK Bioscience Co., Ltd.; Beijing, China) were housed in a controlled environment with a $12 \mathrm{~h}$ light/dark cycle at $23^{\circ} \mathrm{C}$ $\left( \pm 2^{\circ} \mathrm{C}\right)$ and $40-50 \%$ relative humidity with free access to chow and water. Animal experiments were approved by the Animal Ethics Committee of Peking University Health Science Center. Mice were pretreated by intraperitoneal injections of cyclophosphamide once daily at a dose of $100 \mathrm{mg} / \mathrm{kg}$ for 2 consecutive days. Two days later, Ramos cells $(1.5 \times 10 \mathrm{E}+7$ cells in $0.1 \mathrm{~mL}$ PBS $)$ transduced with a lentivirus containing CSRP2 lentiviral activation particles or control lentiviral activation particles were injected subcutaneously into the dorsal right flank of 6-week-old male $\mathrm{Balb} / \mathrm{c}$ nude mice (5 mice/group). Tumor diameters were measured every 2 days until day 15 . Tumor volume $(\mathrm{mmE}+3)$ was estimated by measuring the longest and shortest diameter of the tumor as described [49]. Mice were euthanized on day 15 and tumors surgically removed and photographed.

\section{Statistical analyses}

Differences across groups were compared using the Pearson Chi-square analysis or Fisher exact test for categorical data and Mann-Whitney $U$ test or Student $t$-test for continuous variables. Receiver operating characteristic (ROC) curves were constructed to evaluate the predictive power of transcript levels for diagnosis of B-cell ALL. The Youden Index was used to calculate optimal cutoff points for gene transcript levels in diagnosis of B-cell ALL [50]. Survival functions were estimated by the Kaplan-Meier method and compared by the log-rank test. Cumulative incidences were estimated for relapse to accommodate competing risks. A Cox proportional hazard regression model was used to determine associations between CSRP2 transcript levels and CIR and RFS. Variables with $P>0.1$ were sequentially excluded from the model and those with a $P<0.05$ considered significant. A two-sided $P<0.05$ was considered significant. Analyses were performed by SPSS software version 18.0 (Chicago, IL, USA), Graphpad Prism $^{\text {TM }} 5.01$ (San Diego, California, USA), OriginPro 9.2 (Wellesley Hills, MA, USA), SAS 9.4 software (SAS, Cary, NC, USA) and R software package (version 3.1.2; http:// www.r-project.org).

\section{Abbreviations}

ALL: Acute lymphoblastic leukemia; CSRP2: Cysteine and glycine-rich protein 2; RT-qPCR: quantitative real-time polymerase chain reaction; CIR: cumulative incidence of relapse; RFS: relapse-free survival; MRD: measureable residual disease; ARS: average rank score; RPMI: Roswell Park Memorial Institute; FCM: flow cytometry; pro-B-ALL: early precursor B-cell ALL; pre-B-ALL: precursor B-cell ALL; LAIPs: leukemia-associated aberrant immune phenotypes; MOI: multiplicity of infection; CCK8: Cell Counting Kit-8; GEO: Gene Expression Omnibus (GEO); ROC: Receiver-operator characteristic; GPL: gene plastic.

\section{Authors' contributions}

GRR, KYL, XJH and RPG designed the project and prepared the typescript. SJW performed all experiments and statistical analyses. PZW performed the transcriptome data analyses. YZQ, YRL, YYL, HJ, QJ, XHZ, BJ and LPX provided clinical data.

\section{ACKNOWLEDGMENTS}

We thank all the treating physicians for allowing us to enroll their patients and thank all the patients for allowing us to analyze their data.

\section{CONFLICTS OF INTEREST}

The authors declare that they have no conflicts of interest.

\section{FUNDING}

This study was supported by grants from the National Basic Research Program of China (Grant 2013CB733701), the Key Program of National Natural Science Foundation of China (Grant 81530046) and the National Natural Science Foundation of China (Grant 81570182 and Grant 81270572). RPG acknowledges support from the NIHR Biomedical Research Centre funding scheme.

\section{REFERENCES}

1. Jabbour EJ, Faderl S, Kantarjian HM. Adult acute lymphoblastic leukemia. Mayo Clin Proc. 2005; 80:1517-1527.

2. Alvarnas JC, Brown PA, Aoun P, Ballen KK, Barta SK, Borate U, Boyer MW, Burke PW, Cassaday R, Castro JE, Coccia PF, Coutre SE, Damon LE, et al. Acute Lymphoblastic Leukemia, Version 2.2015. J Natl Compr Canc Netw. 2015; 13:1240-1279.

3. Muhlbacher V, Haferlach T, Kern W, Zenger M, Schnittger S, Haferlach C. Array-based comparative genomic hybridization detects copy number variations with prognostic relevance in $80 \%$ of ALL with normal 
karyotype or failed chromosome analysis. Leukemia. 2016; $30: 318-324$

4. Wang Y, Miller S, Roulston D, Bixby D, Shao L. GenomeWide Single-Nucleotide Polymorphism Array Analysis Improves Prognostication of Acute Lymphoblastic Leukemia/Lymphoma. J Mol Diagn. 2016; 18:595-603.

5. Malumbres R, Fresquet V, Roman-Gomez J, Bobadilla M, Robles EF, Altobelli GG, Calasanz MJ, Smeland EB, Aznar MA, Agirre X, Martin-Palanco V, Prosper F, Lossos IS, et al. LMO2 expression reflects the different stages of blast maturation and genetic features in B-cell acute lymphoblastic leukemia and predicts clinical outcome. Haematologica. 2011; 96:980-986.

6. Sala-Torra O, Gundacker HM, Stirewalt DL, Ladne PA, Pogosova-Agadjanyan EL, Slovak ML, Willman CL, Heimfeld S, Boldt DH, Radich JP. Connective tissue growth factor (CTGF) expression and outcome in adult patients with acute lymphoblastic leukemia. Blood. 2007; 109:3080-3083.

7. Kuhnl A, Gokbuget N, Kaiser M, Schlee C, Stroux A, Burmeister T, Mochmann LH, Hoelzer D, Hofmann WK, Thiel E, Baldus CD. Overexpression of LEF1 predicts unfavorable outcome in adult patients with B-precursor acute lymphoblastic leukemia. Blood. 2011; 118:6362-6367.

8. Kuhnl A, Gokbuget N, Stroux A, Burmeister T, Neumann M, Heesch S, Haferlach T, Hoelzer D, Hofmann WK, Thiel E, Baldus CD. High BAALC expression predicts chemoresistance in adult B-precursor acute lymphoblastic leukemia. Blood. 2010; 115:3737-3744.

9. Wang P, Yang Y, Han W, Ma D. ImmuSort, a database on gene plasticity and electronic sorting for immune cells. Sci Rep. 2015; 5:10370.

10. Jain MK, Kashiki S, Hsieh CM, Layne MD, Yet SF, Sibinga NE, Chin MT, Feinberg MW, Woo I, Maas RL, Haber E, Lee ME. Embryonic expression suggests an important role for CRP2/SmLIM in the developing cardiovascular system. Circ Res. 1998; 83:980-985.

11. Kong Y, Flick MJ, Kudla AJ, Konieczny SF. Muscle LIM protein promotes myogenesis by enhancing the activity of MyoD. Mol Cell Biol. 1997; 17:4750-4760.

12. Chang DF, Belaguli NS, Iyer D, Roberts WB, Wu SP, Dong XR, Marx JG, Moore MS, Beckerle MC, Majesky MW, Schwartz RJ. Cysteine-rich LIM-only proteins CRP1 and CRP2 are potent smooth muscle differentiation cofactors. Dev Cell. 2003; 4:107-118.

13. Hoffmann C, Moreau F, Moes M, Luthold C, Dieterle M, Goretti E, Neumann K, Steinmetz A, Thomas C. Human muscle LIM protein dimerizes along the actin cytoskeleton and cross-links actin filaments. Mol Cell Biol. 2014; 34:3053-3065.

14. Weiskirchen R, Erdel M, Utermann G, Bister K. Cloning, structural analysis, and chromosomal localization of the human CSRP2 gene encoding the LIM domain protein CRP2. Genomics. 1997; 44:83-93.
15. Brandimarte L, Pierini V, Di Giacomo D, Borga C, Nozza F, Gorello P, Giordan M, Cazzaniga G, Te Kronnie G, La Starza R, Mecucci C. New MLLT10 gene recombinations in pediatric T-acute lymphoblastic leukemia. Blood. 2013; 121:5064-5067.

16. Karenko L, Hahtola S, Paivinen S, Karhu R, Syrja S, Kahkonen M, Nedoszytko B, Kytola S, Zhou Y, Blazevic V, Pesonen M, Nevala H, Nupponen N, et al. Primary cutaneous T-cell lymphomas show a deletion or translocation affecting NAV3, the human UNC-53 homologue. Cancer Res. 2005; 65:8101-8110.

17. Midorikawa Y, Tsutsumi S, Taniguchi H, Ishii M, Kobune Y, Kodama T, Makuuchi M, Aburatani H. Identification of genes associated with dedifferentiation of hepatocellular carcinoma with expression profiling analysis. Jpn J Cancer Res. 2002; 93:636-643.

18. Hoffmann C, Mao X, Dieterle M, Moreau F, Al Absi A, Steinmetz A, Oudin A, Berchem G, Janji B, Thomas C. CRP2, a new invadopodia actin bundling factor critically promotes breast cancer cell invasion and metastasis. Oncotarget. 2016; 7:13688-13705. doi: 10.18632/oncotarget.7327.

19. Hu Z, Fan C, Oh DS, Marron JS, He X, Qaqish BF, Livasy C, Carey LA, Reynolds E, Dressler L, Nobel A, Parker $\mathrm{J}$, Ewend $\mathrm{MG}$, et al. The molecular portraits of breast tumors are conserved across microarray platforms. BMC Genomics. 2006; 7:96.

20. Harder L, Otto B, Horstmann MA. Transcriptional dysregulation of the multifunctional zinc finger factor 423 in acute lymphoblastic leukemia of childhood. Genom Data. 2014; 2:96-98.

21. Yu JH, Dong JT, Jia YQ, Jiang NG, Zeng TT, Xu H, Mo XM, Meng WT. Individualized leukemia cell-population profiles in common B-cell acute lymphoblastic leukemia patients. Chin J Cancer. 2013; 32:213-223.

22. Knowles DM 2nd, Tolidjian B, Marboe CC, Mittler RS, Talle MA, Goldstein G. Distribution of antigens defined by $\mathrm{OKB}$ monoclonal antibodies on benign and malignant lymphoid cells and on nonlymphoid tissues. Blood. 1984; 63:886-896.

23. Tursky ML, Beck D, Thoms JA, Huang Y, Kumari A, Unnikrishnan A, Knezevic K, Evans K, Richards LA, Lee E, Morris J, Goldberg L, Izraeli S, et al. Overexpression of ERG in cord blood progenitors promotes expansion and recapitulates molecular signatures of high ERG leukemias. Leukemia. 2015; 29:819-827.

24. Laranjeira AB, de Vasconcellos JF, Sodek L, Spago MC, Fornazim MC, Tone LG, Brandalise SR, Nowill AE, Yunes JA. IGFBP7 participates in the reciprocal interaction between acute lymphoblastic leukemia and BM stromal cells and in leukemia resistance to asparaginase. Leukemia. 2012; 26:1001-1011.

25. De Zen L, Orfao A, Cazzaniga G, Masiero L, Cocito MG, Spinelli M, Rivolta A, Biondi A, Zanesco L, Basso G. Quantitative multiparametric immunophenotyping in acute lymphoblastic leukemia: correlation with specific 
genotype. I. ETV6/AML1 ALLs identification. Leukemia. 2000; 14:1225-1231.

26. Xia M, Zhang H, Lu Z, Gao Y, Liao X, Li H. Key Markers of Minimal Residual Disease in Childhood Acute Lymphoblastic Leukemia. J Pediatr Hematol Oncol. 2016; 38:418-422.

27. Shojaee S, Caeser R, Buchner M, Park E, Swaminathan S, Hurtz C, Geng H, Chan LN, Klemm L, Hofmann WK, Qiu YH, Zhang N, Coombes KR, et al. Erk Negative Feedback Control Enables Pre-B Cell Transformation and Represents a Therapeutic Target in Acute Lymphoblastic Leukemia. Cancer Cell. 2015; 28:114-128.

28. Silveira VS, Scrideli CA, Moreno DA, Yunes JA, Queiroz RG, Toledo SC, Lee ML, Petrilli AS, Brandalise SR, Tone LG. Gene expression pattern contributing to prognostic factors in childhood acute lymphoblastic leukemia. Leuk Lymphoma. 2013; 54:310-314.

29. Kanderova V, Kuzilkova D, Stuchly J, Vaskova M, Brdicka T, Fiser K, Hrusak O, Lund-Johansen F, Kalina T. Highresolution Antibody Array Analysis of Childhood Acute Leukemia Cells. Mol Cell Proteomics. 2016; 15:12461261.

30. Geng H, Brennan S, Milne TA, Chen WY, Li Y, Hurtz C, Kweon SM, Zickl L, Shojaee S, Neuberg D, Huang C, Biswas D, Xin Y, et al. Integrative epigenomic analysis identifies biomarkers and therapeutic targets in adult B-acute lymphoblastic leukemia. Cancer Discov. 2012; 2:1004-1023.

31. Wang P, Han W, Ma D. Electronic Sorting of Immune Cell Subpopulations Based on Highly Plastic Genes. J Immunol. 2016; 197:665-673.

32. Hirasawa Y, Arai M, Imazeki F, Tada M, Mikata R, Fukai K, Miyazaki M, Ochiai T, Saisho H, Yokosuka O. Methylation status of genes upregulated by demethylating agent 5-aza2'-deoxycytidine in hepatocellular carcinoma. Oncology. 2006; 71:77-85.

33. Zhou CZ, Qiu GQ, Wang XL, Fan JW, Tang HM, Sun YH, Wang Q, Huang F, Yan DW, Li DW, Peng ZH. Screening of tumor suppressor genes on 1q31.1-32.1 in Chinese patients with sporadic colorectal cancer. Chin Med J (Engl). 2008; 121:2479-2486.

34. Jin GH, Xu W, Shi Y, Wang LB. Celecoxib exhibits an anti-gastric cancer effect by targeting focal adhesion and leukocyte transendothelial migration-associated genes. Oncol Lett. 2016; 12:2345-2350.

35. Yao QM, Liu KY, Gale RP, Jiang B, Liu YR, Jiang Q, Jiang $\mathrm{H}$, Zhang XH, Zhang MJ, Chen SS, Huang XJ, Xu LP, Ruan GR. Prognostic impact of IKZF1 deletion in adults with common B-cell acute lymphoblastic leukemia. BMC Cancer. 2016; 16:269.

36. Lu DP, Dong L, Wu T, Huang XJ, Zhang MJ, Han W, Chen H, Liu DH, Gao ZY, Chen YH, Xu LP, Zhang YC, Ren HY, et al. Conditioning including antithymocyte globulin followed by unmanipulated HLA-mismatched/ haploidentical blood and marrow transplantation can achieve comparable outcomes with HLA-identical sibling transplantation. Blood. 2006; 107:3065-3073.

37. Huang XJ, Liu DH, Liu KY, Xu LP, Chen H, Han W, Chen YH, Zhang XH, Lu DP. Treatment of acute leukemia with unmanipulated HLA-mismatched/haploidentical blood and bone marrow transplantation. Biol Blood Marrow Transplant. 2009; 15:257-265.

38. Li XM, Zhang LP, Wang YZ, Lu AD, Chang Y, Zhu HH, Qin YZ, Lai YY, Kong Y, Huang XJ, Liu YR. CD38+ CD58- is an independent adverse prognostic factor in paediatric Philadelphia chromosome negative B cell acute lymphoblastic leukaemia patients. Leuk Res. 2016; 43:33-38.

39. Zhao XS, Yan CH, Liu DH, Xu LP, Liu YR, Liu KY, Qin YZ, Wang Y, Huang XJ. Combined use of WT1 and flow cytometry monitoring can promote sensitivity of predicting relapse after allogeneic HSCT without affecting specificity. Ann Hematol. 2013; 92:1111-9.

40. Lai YY, Huang XJ, Li J, Zou P, Xu ZF, Sun H, Shao ZH, Zhou DB, Chen FP, Liu ZG, Zhu HL, Wu DP, Wang C, et al. Standardized fluorescence in situ hybridization testing based on an appropriate panel of probes more effectively identifies common cytogenetic abnormalities in myelodysplastic syndromes than conventional cytogenetic analysis: a multicenter prospective study of 2302 patients in China. Leuk Res. 2015; 39:530-535.

41. Gabert J, Beillard E, van der Velden VH, Bi W, Grimwade D, Pallisgaard N, Barbany G, Cazzaniga G, Cayuela JM, Cave H, Pane F, Aerts JL, De Micheli D, et al. Standardization and quality control studies of 'real-time' quantitative reverse transcriptase polymerase chain reaction of fusion gene transcripts for residual disease detection in leukemia - a Europe Against Cancer program. Leukemia. 2003; 17:2318-2357.

42. Qin YZ, Liu YR, Zhu HH, Li JL, Ruan GR, Zhang Y, Jiang Q, Jiang H, Li LD, Chang Y, Huang XJ, Chen SS. Different kinetic patterns of BCR-ABL transcript levels in imatinibtreated chronic myeloid leukemia patients after achieving complete cytogenetic response. Int J Lab Hematol. 2008; 30:317-323.

43. Ruan GR, Qin YZ, Chen SS, Li JL, Ma X, Chang Y, Wang YZ, Fu JY, Liu YR. Abnormal expression of the programmed cell death 5 gene in acute and chronic myeloid leukemia. Leuk Res. 2006; 30:1159-1165.

44. He YZ, Liang Z, Wu MR, Wen Q, Deng L, Song CY, Wu BY, Tu SF, Huang R, Li YH. Overexpression of EPS8 is associated with poor prognosis in patients with acute lymphoblastic leukemia. Leuk Res. 2015; 39:575-581.

45. Zhang Y, Bao L, Lu J, Liu KY, Li JL, Qin YZ, Chen H, Li LD, Kong Y, Shi HX, Lai YY, Liu YR, Jiang B, et al. The clinical value of the quantitative detection of four cancertestis antigen genes in multiple myeloma. Mol Cancer. $2014 ; 13: 25$.

46. Beillard E, Pallisgaard N, van der Velden VH, Bi W, Dee R, van der Schoot E, Delabesse E, Macintyre E, Gottardi E, Saglio G, Watzinger F, Lion T, van Dongen JJ, et al. 
Evaluation of candidate control genes for diagnosis and residual disease detection in leukemic patients using 'realtime' quantitative reverse-transcriptase polymerase chain reaction (RQ-PCR) - a Europe against cancer program. Leukemia. 2003; 17:2474-2486.

47. Wang W, Zhang Y, Lu W, Liu K. Mitochondrial reactive oxygen species regulate adipocyte differentiation of mesenchymal stem cells in hematopoietic stress induced by arabinosylcytosine. PLoS One. 2015; 10:e0120629.

48. Kim HJ, Lee SY, Kim CY, Kim YH, Ju W, Kim SC. Subcellular localization of FOXO3a as a potential biomarker of response to combined treatment with inhibitors of PI3K and autophagy in PIK3CA-mutant cancer cells. Oncotarget. 2017; 8:6608-6622. doi: 10.18632/ oncotarget.14245.

49. Xie M, Niu JH, Chang Y, Qian QJ, Wu HP, Li LF, Zhang Y, Li JL, Huang XJ, Ruan GR. A novel triple-regulated oncolytic adenovirus carrying PDCD5 gene exerts potent antitumor efficacy on common human leukemic cell lines. Apoptosis. 2009; 14:1086-1094.

50. Carter JV, Pan J, Rai SN, Galandiuk S. ROC-ing along: Evaluation and interpretation of receiver operating characteristic curves. Surgery. 2016; 159:1638-1645. 